\title{
The role of atherectomy in the treatment of lower extremity peripheral artery disease
}

\author{
Anna Franzone ${ }^{1}$, Marco Ferrone ${ }^{1}$, Giuseppe Carotenuto ${ }^{1}$, Andreina Carbone ${ }^{1}$, Laura Scudiero ${ }^{1}$, Federica Serino ${ }^{1}$, \\ Fernando Scudiero ${ }^{1}$, Raffaele Izzo ${ }^{1}$, Raffaele Piccolo ${ }^{1}$, Savio Saviano ${ }^{1}$, Bruno Amato², Cinzia Perrino ${ }^{1}$, \\ Bruno Trimarco', Giovanni Esposito ${ }^{1 *}$
}

From XXV National Congress of the Italian Society of Geriatric Surgery

Padova, Italy. 10-11 May 2012

\begin{abstract}
Background: The incidence of lower extremity peripheral artery disease (LE-PAD) continues to increase and associated morbidity remains high. Despite the significant development of percutaneous revascularization strategies, over the past decade, LE-PAD still represents a unique challenge for interventional cardiologists and vascular surgeons.

Method: Typical features of atherosclerosis that affects peripheral vascular bed (diffuse nature, poor distal runoff, critical limb ischemia, chronic total occlusion) contribute to the disappointing results of traditional percutaneous transluminal angioplasty (PTA). New technologies have been developed in attempt to improve the safety and effectiveness of percutaneous revascularization. Among these, atherectomy, debulking and removing atherosclerotic plaque, offers the potential advantage of eliminating stretch on arterial walls and reducing rates of restenosis.
\end{abstract}

Conclusions: This review summarizes the features and the current applications of new debulking devices.

\section{Introduction}

Peripheral artery disease (PAD) is a common manifestation of systemic atherosclerosis causing a chronic, slowly developing, narrowing of the arteries. Lower extremity peripheral artery disease (LE-PAD) typically affects lower limbs with a frequency that is strongly age-related $(\sim 20 \%$ of the population older than 55) [1]. Clinical manifestations vary from intermittent claudication (pain in the calves while walking that goes away with rest) to critical limb ischemia (CLI), gangrene and, ultimately, limb loss. A significant proportion of patients with PAD have an increased risk of stroke or myocardial infarction [2]. The strong relationship between PAD and coronary heart disease (CHD) is the consequence of common etiology and pathophysiology and has important prognostic implications. Hypoechoic, vulnerable, rupture-prone, plaques in

\footnotetext{
* Correspondence: espogiov@unina.it

'Department of Clinical Medicine, Cardiovascular and Immunological

Sciences, Federico II University, Via S. Pansini 5, 80131, Naples, Italy

Full list of author information is available at the end of the article
}

the femoral arteries represent a marker of cardiovascular risk and are associated to higher incidence of major cardiovascular events [3]. Moreover, successful revascularization of lower limbs by percutaneous transluminal angioplasty (PTA) improves functional status and quality of life and, interestingly, reduces the occurrence of future atherothrombotic events [4]. A number of pharmacological and invasive strategies have been developed over the last decades to improve the clinical outcomes of patients affected by LE-PAD. A "non-interventional" management is the first choice for patients with intermittent claudication: smoking cessation, nutritional counseling, exercise program, strict control of diabetes and hypertension and medication (antiplatelet agent and statins) [5,6]. Mild to moderate benefits have been associated to other pharmacological agents such as pentoxyphylline and cilostazol that resulted effective in increasing walking distance [5]; on the other hand, the intensification of antiplatelet therapy by adding vorapaxar, a novel antiplatelet agent that inhibits cellular actions of thrombin, has shown to reduce 
atherothrombotic events in patients with PAD [7]. In the past, bypass surgery was the standard of care for patients with severe claudication and CLI [8]. Recently, technological advances favoured a significant evolution of percutaneous revascularization therapies that now can be offered as treatment options less invasive than traditional surgery. The optimal endovascular therapy is not well established: there are several options including percutaneous transluminal angioplasty (PTA), stents, drug-coated balloons, crioplasty, percutaneous thrombectomy (rheolytic [9] and aspiration thrombectomy) and atherectomy $[10,11]$. In particular, the promise of atherectomy is to overcome the limitations and complications of traditional angioplasty such as dissection, elastic recoil, and disruption of the internal elastic lamina, resulting in overwhelming neointima and smooth muscle cell proliferation [12]. Unlike balloons and stents, which push plaque into the vessel wall, atherectomy offers the ability to debulk the plaque burden within the vessel [13]. The concept of directional and laser atherectomy is not new and was investigated extensively in the coronary arteries and saphenous vein bypass graft [14]. Despite previous coronary artery data regarding atherectomy may not translate to the peripheral vascular bed because of peculiar dynamic forces acting on these arteries, increased awareness about percutaneous treatment of LE-PAD favoured the development of new debulking devices. Various atherectomy methods are available including plaque excision (directional) atherectomy, laser atheroablation, rotational aspiration/atherectomy and orbital atherectomy. Although data from randomized clinical trials are lacking, this review summarizes the current approach to peripheral atherectomy based on evidences from multicenter prospective registries and describes the mechanism of action of currently available atherectomy devices.

\section{Anatomical features}

Atherosclerosis affecting lower limbs has some specific features: diffuse involvement, superimposed calcification, high incidence of progression to total occlusion, large plaque burden [15]. As our understanding of the complexity of atherosclerotic occlusive disease is evolving (through enhanced use of imaging techniques and growing evidence about molecular mechanisms), new technologies and techniques have been developed to better treat LE-PAD. Femoropopliteal artery disease, in particular, is responsible for the majority of cases of symptomatic LE-PAD. The superficial femoral artery (SFA) is one of the most dynamic vessel of the body and, for this reason, the site of frequent failure of percutaneous strategies. The SFA undergoes many biomechanical stresses such as torsion, compression, flexion and extension by large muscular groups. These factors contribute to make endovascular treatment of this vascular bed especially challenging and are responsible of poor long-term outcomes after percutaneous intervention. Although PTA results effective for the treatment of focal iliac stenosis, pooled primary patency rate following femoropopliteal PTA is of $77 \%$ at 1 year, $61 \%$ at 3 years, and $55 \%$ at 5 years [16]. Factors affecting the long-term patency rates of PTA alone are disease severity, lesion length, poor runoff, diabetes, critical limb ischemia and clinical presentation [17]. In this vascular bed, primary arterial patency is poor with stenting too, despite high procedural acute success. Stent fractures at site of excessive movement (SFA and popliteal arteries) are frequent [18]. Moreover, ultrasound evidence of binary restenosis ranges from $8 \%$ to $40 \%$ between 6 and 24 months [19]. Procedural success rates have been historically lower in the setting of chronic total occlusion that account for up to $20-40 \%$ of patients with LE-PAD undergoing percutaneous treatment [20]. In addition, a number of potential complications (in particular, distal embolization, plaque shift and perforation) may contribute to disappointing results of percutaneous approach to complex infrainguinal disease. Atherectomy, by debulking and removing atherosclerotic plaque cutting or pulverizing atheroma, seems to be a favourable option to increase the spectrum of treatable femoropopliteal lesions such as ostial disease (involving profunda femoral artery), densely calcified plaque, diffuse disease.

\section{Directional atherectomy}

The SilverHawk plaque excision system (ev3 Inc., Plymouth, MN) consists of two major components: a lowprofile catheter and a palm-sized drive unit with on/off thumb switch. They are packaged separately, but used together during the atherectomy procedure. The device is a monorail exchange system over a 0.014 guidewire that is currently available in 7 differents diameter and catheter lengths to allow treatment of femoral, popliteal, tibial, and even pedal vessels [21]. It contains a carbide cutter disc with variable height and rotates at speeds of 8,000 rpm. With the blade spinning, the catheter is slowly advanced across the lesion and the excissed tissue is captured and stored in the tip of device. The cutting sequence can be repeated as many time as necessary to achieve the desired degree of plaque excision. It can be used without the adjunctive use of balloon angioplasty or stents. Significant debulking of the lesion can be achieved without the barotrauma associated with the previous directional atherectomy catheter that uses a balloon opposite the cutting blade to maximize plaque removal [22]. The major indications for the SilverHawk device are focal eccentric lesions, bifurcation lesions of the infrainguinal arteries including the common femoral artery, bypass anastomotic lesions, and long diffuse femoropopliteal lesions including chronic total occlusions. Unfortunately, there have been no randomized clinical trials using this device comparing it to 
angioplasty. Available data come from several registries or single-centre studies [23,24]. The largest, nonrandomized registry, TALON (Treating Peripherals with Silver Hawk Outcome Collections) showed excellent procedural success rates of $97.6 \%$ and $<50 \%$ residual stenosis achieved in $94.7 \%$ of lesions; adjunctive angioplasty was used in $21.7 \%$, and stents were used in $6.3 \%$ of the patients. The overall 12-month freedom from target lesion revascularization (TLR) rate was $80 \%$ [25]. The SilverHawk plaque excision system performs ideally in heavily calcified femoropopliteal lesions; occlusions should be predilated with an undersized balloon to ensure that the wire crosses intraluminally. There are no data supporting the use of this system in the setting of long lesion $(>15 \mathrm{~cm})$ and it should be avoided when subintimal crossing is involved [26]. Table 1.

\section{Rotational atherectomy}

The Jetstream G2 (Pathway Medical Technologies) is a rotational aspiration atherectomy device, uniquely combining rotablation with aspiration capability. The device consists of 2 primary components: a sterile, single use unit consisting of an electrically driven, differentially cutting, aspirating, expandable catheter with a control pod assembly, and a console, with 2 peristaltic aspiration pumps for aspiration and infusion. Isosmolar saline solution is attached to the proximal end of the catheter using
2 dedicated lines. The removed, potentially embolic, material is aspirated at the treatment site, via ports in the fluted tip, into the catheter lumen, and transported to a collection bag located on the device console [27]. The fluted tip rotates at approximately 55,000 rpm with a delivery system that is $8 \mathrm{~F}$ compatible and uses a 0.014 inch guidewire. The device is designed to treat the wide spectrum of disease found in patients with LE-PAD, including hard and soft plaque, calcium, thrombus, and fibrotic lesions. Based on limited data set, the Pathway system appears to be effective in treating SFA atherosclerotic disease, including cases with the presence of significant calcification. In a multicenter registry using the first-generation Pathway device, 172 patients with 210 lesions in nine European centers were treated; the mean lesion length was $35 \mathrm{~mm}$ with moderate to high calcium. The primary endpoint was freedom from device-related serious adverse events (SAEs) at 6 months. TLR at 6 and 12 months was $13 \%$ and $26 \%$, respectively. The ABI (Ankle- Brachial Index) increased from $0.59 \pm 0.21$ at baseline to $0.77 \pm 0.26$ and $0.82 \pm 0.26(\mathrm{P}<.05)$ at 6 and 12 months, respectively [27]. TRUE (Tissue Removal by Ultrasound Evaluation) study evaluated the debulking properties of this device by analyzing changes in the plaque volume and composition and vessel size using intravascular ultrasound (IVUS) and virtual histology (VH).

Table 1 Registries of patients treated with contremporary directional atherectomy

\begin{tabular}{|c|c|c|c|}
\hline & TALON & McKinsey et al & Zeller et al \\
\hline Study type & $\begin{array}{l}\text { Observational, nonrandomized, } \\
\text { multicenter registry }\end{array}$ & Prospective study & $\begin{array}{l}\text { Prospective, nonrandomized, single- } \\
\text { center study }\end{array}$ \\
\hline Patients/Lesions & $728 / 1,517$ & $275 / 579$ & $84 / 131$ \\
\hline Lesion location & SFA/below-the-knee & Infrainguinal & SFA/popliteal \\
\hline Average lesion length & $8.4 \mathrm{~cm}$ & $\begin{array}{l}\text { SFA, } 9.16 \mathrm{~cm} \text {; popliteal, } 3.77 \mathrm{~cm} \text {; } \\
\text { tibial, } 4.64 \mathrm{~cm}\end{array}$ & $9-10.6 \mathrm{~cm}$ \\
\hline Lesion characteristics & De novo & De novo & $\begin{array}{l}\text { Group 1, 34\%;a group 2, 33\%;b } \\
\text { group 3, 33\%c }\end{array}$ \\
\hline Stand-alone treatment & - & $64.8 \%$ & -— \\
\hline Adjunctive balloon angioplasty & $21.7 \%$ & $24.3 \%$ & $59 \%$ \\
\hline Adjunctive stenting & $6.3 \%$ & $7.5 \%$ & $6 \%$ \\
\hline $\begin{array}{l}\text { Primary patency (by duplex) at } \\
12 \text { months }\end{array}$ & - - & $62.2 \%$ & $\begin{array}{l}\text { Group 1, 84\%;a group 2, 54\%;b } \\
\text { group 3, 54\%c }\end{array}$ \\
\hline 18-month primary patency & - - & $52.7 \%$ & $\begin{array}{l}\text { Group 1, 73\%;a group 2, 42\%;b } \\
\text { group 3, 49\%c }\end{array}$ \\
\hline TLR at 12 months & $80 \%$ & - & $\begin{array}{l}\text { Group 1, 16\%;a group 2, 44\%;b } \\
\text { group 3, 47\%c }\end{array}$ \\
\hline TLR at 18 months & - - & - - & $\begin{array}{l}\text { Group 1, 22\%;a group 2, 56\%;b } \\
\text { group 3, } 49 \% \text { c }\end{array}$ \\
\hline Claudication & -— & $36.7 \%$ & - - \\
\hline$\underline{\mathrm{CLI}}$ & - - & $63.3 \%$ & - \\
\hline Device-related SAEs & $5.3 \%$ & $4.1 \%$ & $3.8 \%$ \\
\hline
\end{tabular}

aGroup 1 was de novo lesions.

bGroup 2 was native vessel restenosis.

cGroup 3 was in-stent restenosis. 
Freedom from target lesion revascularization (TLR) at 6 and 12 months was also evaluated. In this study atherectomy with the Jetstream G2 system resulted in substantial plaque reduction by removing fibrotic and fibro-fatty plaque [28]. Furthermore, there were no major complications during the procedure or index hospitalization, and an acceptable TLR rate was observed after a 1-year follow-up. Table 2.

\section{Orbital atherectomy}

Diamondback $360^{\circ}$ Orbital Atherectomy System, OAS, (Cardiovascular Systems, Inc. [CSI], St. Paul, MN) is an orbital atherectomy system that consists of an eccentric, diamond-grit-coated, abrasive crown that creates an ablative surface proportional to the displaced radius of the crown through centrifugal force when the device is rotated at various speeds [29]. It can create a lumen that is $>1.75$ times the crossing profile depending on the size of the grit and the eccentricity of the offset. The greater the speed of the crown, the larger the arc of debulking is and, ultimately, the resultant lumen size [30]. The centrifugal force and the differential sanding allow the removing of thin layer of the calcific plaque to each pass of the device while the differential sanding discriminates between the calcific or fibrocalcific lesion and the normal arterial wall thanks to the elastic compliance of the arterial tissue adjacent to the plaque. OAS is a system which includes a low profile catheter with an eccentrically mounted diamond-coated crown, a control handle with control knob, a flexible drive shaft, and a protective sheath. The mechanism of OAS is based on the rotation of the flexible drive shaft and of the crown over a guide wire (ViperWire Advance). The guide wire operates in this way as the rail on which the catheter rotates, while the sheat covers the drive shaft and allows the delivery of saline solution and medications in the treatment area. The movement and the rotating speed of the crown is managed through the external control unit. The control unit is the user interface and regulates air pressure to drive the speed turbine located in the control handle rotating the drive shaft and the crown to speed up to $20.000 \mathrm{rpm}$. A constant flow of saline solution is delivered by a roller pump in the control unit which lubrificates the device and helps to flush the artery. The high speed rotation, together with the diamond coated crown modifies the morphology of the fibrocalcific plaque and acts as an orbital atherectomy sanding the profile of the lesion at each pass of the device. This device uniquely delivers $360^{\circ}$ of plaque removal and may be effective in calcified plaque [31]. The off-centered shape of the crown allows for continuous blood flow around the device, which allows particles to move downstream, and reduces localized heating of the vessel [30]. OASIS (Orbital Atherectomy System for the Treatment of Peripheral

Table 2 Registries of patients treated with rotational and orbital atherectomy

\begin{tabular}{|c|c|c|c|c|}
\hline \multirow[b]{2}{*}{ Study } & \multicolumn{2}{|c|}{ Pathway System } & \multicolumn{2}{|c|}{ Diamondback $360^{\circ}$ OAS (CSI) } \\
\hline & $\begin{array}{l}\text { Pilot } \\
\text { study }\end{array}$ & $\begin{array}{l}\text { Multicenter, prospective } \\
\text { registry }\end{array}$ & OASIS trial & PAD \| \\
\hline Patients/lesions & $15 / 15$ & $172 / 210$ & $124 / 201$ & $66 / 86$ \\
\hline Lesion location & $47 \%$ SFA & $64 \%$ SFA & $\begin{array}{l}\text { 94\% popliteal and } \\
\text { tibial }\end{array}$ & $\begin{array}{l}\text { Reference vessel diameter of } 1.5-4 \\
\mathrm{~mm}\end{array}$ \\
\hline Mean lesion length & $61 \mathrm{~mm}$ & $35 \mathrm{~mm}$ & $30 \mathrm{~mm}$ & $35 \mathrm{~mm}$ \\
\hline Calcified & - - & -— & $55 \%$ & - - \\
\hline Chronic total occlusion & - - & - & $12 \%$ & - \\
\hline Stand-alone treatment & $6(40 \%)$ & $33 \%$ & $58.2 \%$ & $39.5 \%$ \\
\hline Adjunctive balloon angioplasty & $7(47 \%)$ & $59 \%$ & $39.3 \%$ & $60.5 \%$ \\
\hline Adjunctive stenting & $2(13 \%)$ & $7 \%$ & $2.50 \%$ & - \\
\hline $\begin{array}{l}\text { Primary patency (by duplex) at } 6 \\
\text { months }\end{array}$ & $73 \%$ & - & - & - \\
\hline TLR at 6 months & $0 \%$ & $13 \%$ & $2.4 \%$ & $13.6 \%$ \\
\hline TLR at 12 months & - - & $26 \%$ & - - & - - \\
\hline Preprocedure ABI & $0.54 \pm 0.3$ & $0.59 \pm 0.2$ & $0.68 \pm 0.2$ & - \\
\hline $\mathrm{ABI}$ at 6 months & $0.81 \pm 0.2$ & $0.77 \pm 0.3$ & $0.82 \pm 0.1$ & - - \\
\hline $\mathrm{ABI}$ at 12 months & -1 & $0.82 \pm 0.3$ & - & - \\
\hline MAEsa at 1 month & - - & -1 & $4(3.2 \%)$ & - - \\
\hline MAEsa at 6 months & & $15 \%$ & $13(10.4 \%)$ & $37.9 \%$ \\
\hline Device-related SAEs & & & $2.9 \%$ & $6 \%$ \\
\hline
\end{tabular}

aDeath, myocardial infarction, amputation, or repeat revascularization. 
Vascular Stenosis), a nonrandomized prospective Investigational Device Exemption study, enrolled 124 patients (202 lesions) at 17 sites in the United States between January 2006 and January 2007; procedural success (achievement of $<30 \%$ residual diameter stenosis) was met in $90.1 \%$ of lesions. Orbital atherectomy was used alone in $57.7 \%$ of lesions, with adjunctive therapy (PTA and/or stenting) used in $42.3 \%$. Symptom- driven TLR at 6 months was $2.4 \%$; the mean Rutherford categories were $3 \pm 1.3$ at baseline and $1.2 \pm 1.5$ at 6 months. Interestingly, $14 \%$ of the patients demonstrated worse $\mathrm{ABI}$ at the end of 30 days compared to baseline. This detriment in ABI may be secondary to procedural complications due to hemolysis or distal embolization [32]. Obviously, this procedure can imply different intra-procedurals complications. Slow flow is a common complication in every kind of atherectomy procedure for the liberation of debris clogging microcirculation. Several testing in vivo were conducted to evaluate the impact of sanding and of liberation of debris during the orbital atherectomy. Both the classic and the solid crown were tested in this sense, and both showed to generate particles of a diameter smaller than 9.5 micron which is the diameter of the capillars. Therefore the most of the particles can be flushed through the capillary bed. The effect of the generation of the particles during the procedure, however, can be minimized ensuring proper orbital sanding technique and using vasodilators. Orbital sanding speed should be increased gradually and for short period of time, while vasodilators drugs should be used at the beginning of the procedure and during intervals helping the dispersion of particles. Hemolysis is another complication associated to high-speed orbital atherectomy. Nevertheless studies in orbital sanding system showed a minimal and transient haemolysis. OASIS trial did not show clinical significant hemolysis associated to OAS atherectomy, and even if laboratory markers did fluctuated after the procedure, this changes were transient and resolved spontaneously. Arterial spasm occurs during the procedure in the site corresponding the orbital atherectomy or at site just adiacent. Pain can occur in the site of the treatment and it is most likely due to the activation of the adventitial nerve receptors as the media and intima are not innervated. Obviously the choise of proper crown dimension and limiting the orbital speed can prevent the onset of pain reducing, in this way, the diameter of the rotation so that diminishing the contact between the crown and the wall of the vessel. The contraindications to the use of OAS atherectomy are the presence of thrombus or dissection, intra-stent or intra-graft stenosis, and caution should be used in vessels with severe tortuosity. In conclusion, OAS represents a safe, efficacious and cost-effective endovascular method for LE-PAD treatment. Its use should be implemented from the correct evaluation of the proper device and from the choose of proper drug treatment to improve the treatment success and to minimize the periprocedural adverse events. Table 2.

\section{Atherectomy and restenosis: molecular mechanisms and clinical outcomes}

This review shows the great improvement in PAD management due to percutaneous treatment. Actually, even if all the techniques discussed below have a good therapeutic impact in terms of regression of LE-PAD as well as in term of days of recovery, they all suffer of an important limitation, the restenosis of the treated area. This drawback is reported in up to $60 \%$ of primarily successful PTA [33]. Regardless of the type of intervention, stenosis or restenosis develops in a significant number of patients, often leading to limb loss or death and it remains the "Achille's heel" of the application of these procedures. Restenosis is arbitrarily defined as a greater than $50 \%$ narrowing of vessel diameter compared with a reference artery. The clear mechanism of restenosis is not perfectly known but several evidences suggest a strong link between restenosis itself and vessel inflammation. This theory is feeding the interest toward the identification of makers of inflammations, which may have a diagnostic but especially prognostic role in the managing of the vessels restenosis. The plasma proteins, $C$-reactive protein (CRP), serum amyloid A (SAA), and fibrinogen are sensitive, specific, and fast reacting markers of acute phase reaction [34] and provide an indirect measure of a cytokine dependent inflammatory process of the arterial wall [35]. Restenosis is mainly due to excessive neointima formation [12]. Percutaneous intervention leads to mechanical injury that induces vascular inflammation, which stimulates vascular smooth muscle cell proliferation and extracellular matrix deposition, resulting in neointimal thickening and restenosis [36]. It has been demonstrated that in a rat model of carotid artery dilation by a balloon catheter, the first step in allowing vascular smooth muscle cell (SMC) proliferation from the tunica media to the intima is the occurrence of internal elastic lamina (IEL) rupture [12]. During arterial catheterization, the endothelial layer is removed by balloon dilation, resulting in the loss of this important antithrombogenic layer. Moreover, endothelial denudation results in the exposure of the subendothelial matrix to flowing blood. Platelets and fibrinogen immediately adhere to the surface of the injured vessel, inducing platelets aggregation and activation. Activated platelets release various cytokines, chemokines, and growth factors, which initiate smooth muscle cell (SMC) proliferation and leukocyte recruitment to the injured vessel segment. Substances released or activated after injury include platelet-derived growth factor (PDGF), transforming growth factor (TGF)$\beta$, interleukin (IL)-1, IL-6, IL-8, thrombin, adenosine diphosphate, and thromboxane A2 [33,37]. The initial 
tethering and rolling of leukocytes on platelets is mediated through binding of the leukocyte receptor P-selectin glycoprotein ligand-1 to platelet $\mathrm{P}$-selectin. Rolling leukocytes stop and firmly attach to adherent platelets when the leukocyte integrin Mac-1 (CD11b/CD18) binds to platelet glycoprotein Ib-alpha or to fibrinogen bound to the platelet glycoprotein IIb/IIIa [36]. After, there is smooth muscle cell (SMC) proliferation and migration to the intima. Migrated smooth muscle cells (SMCs) contribute to the intimal thickening by the excessive synthesis of extracellular matrix (ECM) and proliferation. Intimal SMCs are derived primarily from the media, but they may also be derived from adventitial myofibroblasts, pericytes associated with infiltrating microvessels, and circulating progenitor cells. The pathway for SMC proliferation is an integrated mechanism involving several known and as yet unidentified cell-signalling pathways coupled to the cell cycle. Peptides binding to tyrosine kinase receptors are possibly the most potent mitogens for smooth muscle cells (SMCs) and they modulate a variety of signalling pathways, including ras [38], raf, the mitogen activated protein kinase (MAPK) cascade, the phosphoinositol-3 kinase- protein kinase B pathway and the diacylglycerol protein kinase $C$ pathway $[35,39,40]$. It was previously described the opposite effects of SMCs proliferation of two intracellular pathways. In fact, it was showed that the stimulation of Ras-MAPKs proteins induces the proliferation of SMCs $[38,34]$ that are, in contrast, inhibited by the activation of cAMP-PKA signaling [41,42]. Furthermore hyperinsulinemia, through activation of the ras-MAPK pathway, rather than hyperglycemia per se, appears to be crucial in determining the exaggerated neointimal response after balloon angioplasty in diabetic animals [43]. Moreover, new growing knowledge about molecular mechanism of restenosis highlight the role of micro-RNA in vascular remodeling [44].

Several studies show the rate of restenosis after baloon angioplasty, after stent implantation and after atherectomy using different types of devices. Ablative therapy deserves particular relevance and several studies have investigated the rates of occurrence of restenosis after debulking procedures. TALON (Treating Peripherals with Silver Hawk Outcome Collections) study involved 601 patients showing a rate of survival free of TLR at 6 months of $90 \%$ and at 12 months of $80 \%$ [25]. Sarac et al. recruited 167 patients treated with Silver Hawk device in tibial arteries. Cumulative 1-year primary and secondary patency rates were $43 \%$ and $57 \%$, respectively [45]. An interesting result comes from Shammas et al. trial which demonstrates the inferiority of Silver Hawk atherectomy versus balloon angioplasty. In this trial 72 patients were divided in two groups. The first group $(n=38)$ were treated with Silver Hawk atherectomy, the second group $(n=35)$ were treated with conventional balloon angioplasty. Primary patency at 2 months was of $34 \%$ in the first group versus $56 \%$ in the second group [46]. Another kind of device was investigated from Scheiner et al. who studied the impact of Laser ablative atherectomy in SFA arteries. They reported their experience with the excimer laser in recanalizing occluded SFA arteries: the technical success was $90.5 \%$, but primary patency at 1 year was only $33.6 \%$. The 1 year assisted primary and secondary patency rates were $65.1 \%$ and $75.9 \%$, respectively. In addition, short SFA occlusions $(1-10 \mathrm{~cm})$ treated with the excimer laser demonstrated primary, assisted primary, and secondary patency rates of $49.2 \%$, $76.5 \%$, and $86.3 \%$, respectively, at 36 -month follow-up [47]. Stoner et al. reported their data on 40 patients treated with laser atherectomy; average follow-up was $461 \pm$ 49 days. The indication for laser atherectomy was critical limb ischemia in 26 (65\%) and claudication in 11 (35\%) patients. A total of 47 lesions in the femoropopliteal and infrapopliteal arterial segments were treated. Adjunctive angioplasty was used in $75 \%$ of cases. The overall 12 month primary patency was 44\% [48]. Two further trials investigated rotational atherectomy: Myers et al. treated 72 patients using rotablator and showed a primary patency of $47 \%$ at 6 months, $31 \%$ at 12 months and of $18,5 \%$ at 24 months [49]. In the OASIS TRIAL, rotational atherectomy with Diamondback $360^{\circ}$ was associated with a rate of TLR of $0,9 \%$ at 6 months, but further data are needed to understand the impact of this device on long term patency.

\section{Procedural risks and complications: how to optimize peripheral atherectomy}

The risks associated with atherectomy of the superficial femoral, popliteal, anterior tibial, posterior tibial and peroneal arteries may include, but are not limited to the following: arterial dissection, arterial perforation, arterial rupture, arterial spasm, arterio-venous (AV) fistula, bleeding complications, embolism and/or arterial thrombosis, emergency or non-emergency arterial bypass surgery, entry site complications, restenosis of the treated segment, total occlusion of the peripheral artery, vascular complications which may require surgical repair [50,51] . As with any device requiring mechanical deployment and retraction, there exists a risk of mechanical failure of the device resulting in potential surgical intervention. All of the above could cause prolonged illness, permanent impairment of daily function or, in rare cases, death. Possible treatments could include vascular surgery. Extensive reliability engineering testing has been performed on the study device to mitigate risks to the subject due to product failure. Risks of atherectomy may be further limited by providing medications such as aspirin or clopidogrel and continuing to monitor subjects following atherectomy $[52,53]$. Mechanical atherectomy may be associated with 
high risk of peripheral embolization. The risk of distal embolization is more common in the acute and subacute peripheral vascular intervention. Embolic protection devices (EPD) have been used successfully in many circumstances. In the femoropopliteal system the size of the common femoral can vary $(3-6 \mathrm{~mm})$, then some vessel are too small for most distal protection. The maximum diameter is 5 to $6.3 \mathrm{~mm}$ depending upon the device used [54]. The use of EPD in acute lower-extremity ischemia is considered a reasonable strategy to prevent distal thromboembolism and occlusion of the distal circulation [52]. The embolization rate reported by TALON registry was $0.1 \%$ [25]. The use of distal filter has been always associated to retrievement of debris consisting of atherectomy-cut pieces of plaque [55]. In the PROTECT (Preventing Lower Extremity Distal Embolization Using Embolic Filter Protection) registry 40 patients with 56 lesions underwent angioplasty/ stenting or atherectomy, with 1 filter employed per patient. Clinically significant macrodebris ( $>2 \mathrm{~mm}$ in diameter) was found in $27.6 \%$ of the angioplasty/ stenting patients and $90.9 \%$ of the atherectomy patients [56]. Some recommendations to optimize the result of peripheral atherectomy and minimize the risk of procedural complications are listed below: use contralateral access in most cases but, for distal lesions, prefer an antegrade approach for a better control of tip; make slow and methodical cuts and advance the cutting blade slowly; ensure adequate anticoagulation (ACT, activated clotting times of 275 to 300 seconds) to avoid thrombotic complications during the procedure.

\section{Conclusions}

Recent technological advances have made it possible to increase the spectrum of treatable peripheral arterial lesions with high acute procedure success rates. However, the choice of the best endovascular strategy for the treatment of LE-PAD still remains challenging because of the specific features of this vascular bed and the diffuse nature of the atherosclerotic process. Durability and long-term patency remain the major challenges to therapy in LEPAD endovascular treatment significant advances: despite significant advances and availability of new devices, the principal failure continues to be recurrent restenosis. The role of atherectomy may be to overcome the limitation of balloon angioplasty and stent placement. A number of debulking modalities and devices are now available with good procedural results. Long term outcomes need to be addressed by large, randomized trials.

\section{List of abbreviations}

ABI: ankle-brachial index; AV: arterio-venous; CHD: coronary heart disease; CLI: critical limb ischemia; CRP: C-reactive protein; ECM: extracellular matrix; EPD: embolic protection device; IEL: internal elastic lamina; IL: interleukin; IVUS: intravascular ultrasound; LE-PAD: lower extremity peripheral arterial disease; MAPK: mitogen activated protein kinase; OAS: orbital atherectomy system; PAD: peripheral artery disease; PDGF: platlet-derived growth factor;
PTA: percutaneous transluminal angioplasty; PTCA: percutaneous transluminal coronary angioplasty; SAA: serum amyloid A; SAEs: serious adverse events; SFA: superficial femoral arthery; SMC: smooth muscle cell; TGF- $\beta$ : transforming growth factor; TLR: target lesion revascularization; VH: virtual histology.

\section{Acknowledgements}

This article has been published as part of BMC Surgery Volume 12 Supplement 1, 2012: Selected articles from the XXV National Congress of the Italian Society of Geriatric Surgery. The full contents of the supplement are available online at http://www.biomedcentral.com/bmcsurg/supplements/12/s1.

\section{Author details}

${ }^{1}$ Department of Clinical Medicine, Cardiovascular and Immunological Sciences, Federico II University, Via S. Pansini 5, 80131, Naples, Italy. ${ }^{2}$ Department of General, Geriatric, Oncologic Surgery and Advanced Technologies, Federico II University, Via S. Pansini 5, 80131, Naples, Italy.

\section{Authors' contributions}

AF: conception and design, interpetration of data, given final approval of the version to be published, MF, GC, AC, LS, FS RI, RP, SS: acquisition of data, drafting the manuscript, given final approval of the version to be published, BA, BT, CP: critical revision, interpretation of data, given final approval of the version to be published, GE: conception and design, critical revision, given final approval of the version to be published.

\section{Competing interests}

The authors declare that they have no competing interests.

Published: 15 November 2012

\section{References}

1. Meijer WT, Hoes AW, Rutgers D, Bots ML, Hofman A, Grobbee DE: Peripheral arterial disease in the elderly: The Rotterdam Study. Arterioscler Thromb Vasc Biol 1998, 18(2):185-192.

2. Criqui MH, Langer RD, Fronek A, Feigelson HS, Klauber MR, McCann TJ, Browner D: Mortality over a period of 10 years in patients with peripheral arterial disease. N Engl J Med 1992, 326(6):381-386.

3. Schiano V, Sirico G, Giugliano G, Laurenzano E, Brevetti L, Perrino C, Brevetti G, Esposito G: Femoral plaque echogenicity and cardiovascular risk in claudicants. JACC Cardiovasc Imaging 2012, 5(4):348-357.

4. Giugliano G, Di Serafino L, Perrino C, Schiano V, Laurenzano E, Cassese S, De Laurentis M, Schiattarella GG, Brevetti L, Sannino A, et al: Effects of successful percutaneous lower extremity revascularization on cardiovascular outcome in patients with peripheral arterial disease. Int J Cardiol 2012.

5. European Stroke O, Authors/Task Force M, Tendera M, Aboyans V, Bartelink ML, Baumgartner I, Clement D, Collet JP, Cremonesi A, De Carlo M, et al: ESC Guidelines on the diagnosis and treatment of peripheral artery diseases: Document covering atherosclerotic disease of extracranial carotid and vertebral, mesenteric, renal, upper and lower extremity arteries: the Task Force on the Diagnosis and Treatment of Peripheral Artery Diseases of the European Society of Cardiology (ESC). Eur Heart J 2011, 32(22):2851-2906.

6. Franzone A, Schiattarella GG, Capretti G, Sorrentino S, Sannino A, Perrino C, Esposito G, Chiariello M: Biological effects of statins in atherosclerosis. Trends in medicine 2009, 9(1):32-45.

7. Morrow DA, Braunwald E, Bonaca MP, Ameriso SF, Dalby AJ, Fish MP, Fox KA, Lipka LJ, Liu X, Nicolau JC, et al: Vorapaxar in the secondary prevention of atherothrombotic events. N Engl J Med 2012, 366(15):1404-1413.

8. Dormandy JA, Rutherford RB: Management of peripheral arterial disease (PAD). TASC Working Group. TransAtlantic Inter-Society Consensus (TASC). J Vasc Surg 2000, 31(1 Pt 2):S1-S296.

9. Borgia F, Di Serafino L, Sannino A, Gargiulo G, Schiattarella GG, De Laurentis M, Scudiero L, Perrino C, Piscione F, Esposito G, et al: AngioJet rheolytic thrombectomy for acute superficial femoral artery stent or femoropopliteal by-pass thrombosis. Monaldi Arch Chest Dis 2010, 74(2):76-81.

10. Mahmud E, Cavendish JJ, Salami A: Current treatment of peripheral arterial disease: role of percutaneous interventional therapies. Journal of the American College of Cardiology 2007, 50(6):473-490. 
11. Ahn SS, Concepcion B: Current status of atherectomy for peripheral arterial occlusive disease. World journal of surgery 1996, 20(6):635-643.

12. Curcio A, Torella D, Indolfi C: Mechanisms of smooth muscle cell proliferation and endothelial regeneration after vascular injury and stenting: approach to therapy. Circulation journal : official journal of the Japanese Circulation Society 2011, 75(6):1287-1296.

13. Rogers JH, Laird JR: Overview of new technologies for lower extremity revascularization. Circulation 2007, 116(18):2072-2085.

14. Das TS, Beregi JP, Garcia LA, Abul-Khoudoud O, Laird JR, Lumsden AB, Lyden SP, Mewissen MW, Shimshak TM: Infrainguinal lesion-specific device choices: round-table discussion. Journal of endovascular therapy : an official journal of the International Society of Endovascular Specialists 2006, 13(Suppl 2):I160-71.

15. Walsh DB, Powell RJ, Stukel TA, Henderson EL, Cronenwett JL: Superficial femoral artery stenoses: characteristics of progressing lesions. J Vasc Surg 1997, 25(3):512-521.

16. Norgren L, Hiatt WR, Dormandy JA, Nehler MR, Harris KA, Fowkes FG, Group TIW, Bell K, Caporusso J, Durand-Zaleski I, et al: Inter-Society Consensus for the Management of Peripheral Arterial Disease (TASC II). Eur J Vasc Endovasc Surg 2007, 33(Suppl 1):S1-75.

17. Laird JR: Limitations of percutaneous transluminal angioplasty and stenting for the treatment of disease of the superficial femoral and popliteal arteries. Journal of endovascular therapy: an official journal of the International Society of Endovascular Specialists 2006, 13(Suppl 2):II30-40.

18. Scheinert D, Scheinert S, Sax J, Piorkowski C, Braunlich S, Ulrich M, Biamino G, Schmidt A: Prevalence and clinical impact of stent fractures after femoropopliteal stenting. Journal of the American College of Cardiology 2005, 45(2):312-315.

19. Mewissen MW: Self-expanding nitinol stents in the femoropopliteal segment: technique and mid-term results. Tech Vasc Interv Radiol 2004, $7(1): 2-5$.

20. Morgenstern BR, Getrajdman GI, Laffey KJ, Bixon R, Martin EC: Total occlusions of the femoropopliteal artery: high technical success rate of conventional balloon angioplasty. Radiology 1989, 172(3 Pt 2):937-940.

21. Garcia LA, Lyden SP: Atherectomy for infrainguinal peripheral artery disease. Journal of endovascular therapy: an official journal of the International Society of Endovascular Specialists 2009, 16(2 Suppl 2):II105-115.

22. Massmann A, Katoh M, Shayesteh-Kheslat R, Buecker A: Mechanical Recanalization of Subacute Vessel Occlusion in Peripheral Arterial Disease with a Directional Atherectomy Catheter. Cardiovascular and interventional radiology 2012.

23. McKinsey JF, Goldstein L, Khan HU, Graham A, Rezeyat C, Morrissey NJ, Sambol E, Kent KC: Novel treatment of patients with lower extremity ischemia: use of percutaneous atherectomy in 579 lesions. Ann Surg 2008, 248(4):519-528.

24. Zeller T, Rastan A, Sixt S, Schwarzwalder U, Schwarz T, Frank U, Burgelin K, Muller $C$, Rothenpieler $U$, Flugel $P C$, et al: Long-term results after directional atherectomy of femoro-popliteal lesions. Journal of the American College of Cardiology 2006, 48(8):1573-1578.

25. Ramaiah V, Gammon R, Kiesz S, Cardenas J, Runyon JP, Fail P, Walker C, Allie DE, Chamberlin J, Solis M, et al: Midterm outcomes from the TALON Registry: treating peripherals with SilverHawk: outcomes collection. Journal of endovascular therapy : an official journal of the International Society of Endovascular Specialists 2006, 13(5):592-602.

26. Zeller T, Rastan A, Schwarzwalder U, Frank U, Burgelin K, Amantea P Muller $C$, Krankenberg $H$, Flugel PC, Neumann FJ: Midterm results after atherectomy-assisted angioplasty of below-knee arteries with use of the Silverhawk device. J Vasc Interv Radiol 2004, 15(12):1391-1397.

27. Zeller T, Krankenberg H, Rastan A, Sixt S, Schmidt A, Tubler T, Schwarz T, Frank U, Burgelin K, Schwarzwalder U, et al: Percutaneous rotational and aspiration atherectomy in infrainguinal peripheral arterial occlusive disease: a multicenter pilot study. Journal of endovascular therapy : an official journal of the International Society of Endovascular Specialists 2007, 14(3):357-364

28. Singh T, Koul D, Szpunar S, Torey J, Dhabuwala J, Saigh L, Pires LA, Davis T: Tissue removal by ultrasound evaluation (the TRUE study): the Jetstream G2 system post-market peripheral vascular IVUS study. The Journal of invasive cardiology 2011, 23(7):269-273.

29. Adams GL, Khanna PK, Staniloae CS, Abraham JP, Sparrow EM: Optimal techniques with the Diamondback 360 degrees System achieve effective results for the treatment of peripheral arterial disease. Journal of cardiovascular translational research 2011, 4(2):220-229.

30. Heuser RR: Treatment of lower extremity vascular disease: the Diamondback 360 degrees Orbital Atherectomy System. Expert review of medical devices 2008, 5(3):279-286.

31. Korabathina R, Mody KP, Yu J, Han SY, Patel R, Staniloae CS: Orbital atherectomy for symptomatic lower extremity disease. Catheterization and cardiovascular interventions : official journal of the Society for Cardiac Angiography \& Interventions 2010, 76(3):326-332.

32. Safian RD, Niazi K, Runyon JP, Dulas D, Weinstock B, Ramaiah V, Heuser R, Investigators O: Orbital atherectomy for infrapopliteal disease: device concept and outcome data for the OASIS trial. Catheterization and cardiovascular interventions : official journal of the Society for Cardiac Angiography \& Interventions 2009, 73(3):406-412.

33. Min SK, Kenagy RD, Clowes AW: Induction of vascular atrophy as a novel approach to treating restenosis. A review. J Vasc Surg 2008, 47(3):662-670.

34. Indolfi C, Avvedimento EV, Rapacciuolo A, Esposito G, Di Lorenzo E, Leccia A, Pisani A, Chieffo A, Coppola A, Chiariello M: In vivo gene transfer: prevention of neointima formation by inhibition of mitogen-activated protein kinase kinase. Basic research in cardiology 1997, 92(6):378-384.

35. Mitra AK, Agrawal DK: In stent restenosis: bane of the stent era. J Clin Pathol 2006, 59(3):232-239.

36. Inoue T, Croce K, Morooka T, Sakuma M, Node K, Simon DI: Vascular inflammation and repair: implications for re-endothelialization, restenosis, and stent thrombosis. JACC Cardiovasc Interv 2011, 4(10):1057-1066.

37. Petretta M, Condorelli GL, Spinelli L, Scopacasa F, de Caterina M, Leosco D, Vicario ML, Bonaduce D: Circulating levels of cytokines and their site of production in patients with mild to severe chronic heart failure. American heart journal 2000, 140(6):E28.

38. Indolfi C, Avvedimento EV, Rapacciuolo A, Di Lorenzo E, Esposito G, Stabile E, Feliciello A, Mele E, Giuliano P, Condorelli G, et al: Inhibition of cellular ras prevents smooth muscle cell proliferation after vascular injury in vivo. Nat Med 1995, 1(6):541-545.

39. Indolfi C, Stabile E, Perrino C, Chiariello M: Mechanisms of restenosis after angioplasty and approach to therapy (Review). International journal of molecular medicine 1998, 2(2):143-148

40. Indolfi C, Esposito G, Stabile E, Cavuto L, Pisani A, Coppola C, Torella D,

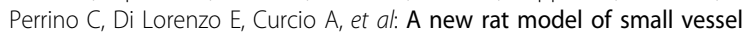
stenting. Basic research in cardiology 2000, 95(3):179-185.

41. Indolfi C, Avvedimento EV, Di Lorenzo E, Esposito G, Rapacciuolo A, Giuliano P, Grieco D, Cavuto L, Stingone AM, Ciullo l, et al: Activation of CAMP-PKA signaling in vivo inhibits smooth muscle cell proliferation induced by vascular injury. Nat Med 1997, 3(7):775-779.

42. Indolfi C, Stabile E, Coppola C, Gallo A, Perrino C, Allevato G, Cavuto L, Torella D, Di Lorenzo E, Troncone G, et al: Membrane-bound protein kinase $A$ inhibits smooth muscle cell proliferation in vitro and in vivo by amplifying CAMP-protein kinase A signals. Circulation research 2001, 88(3):319-324

43. Indolfi C, Torella D, Cavuto L, Davalli AM, Coppola C, Esposito G, Carriero MV, Rapacciuolo A, Di Lorenzo E, Stabile E, et al: Effects of balloon injury on neointimal hyperplasia in streptozotocin-induced diabetes and in hyperinsulinemic nondiabetic pancreatic islet-transplanted rats. Circulation 2001, 103(24):2980-2986.

44. laconetti C, Polimeni A, Sorrentino S, Sabatino J, Pironti G, Esposito G, Curcio A, Indolfi C: Inhibition of miR-92a increases endothelial proliferation and migration in vitro as well as reduces neointimal proliferation in vivo after vascular injury. Basic research in cardiology 2012, 107(5):296.

45. Sarac TP, Altinel O, Bannazadeh M, Kashyap V, Lyden S, Clair D: Midterm outcome predictors for lower extremity atherectomy procedures. J Vasc Surg 2008, 48(4):885-890, discussion 890

46. Shammas NW, Lam R, Mustapha J, Ellichman J, Aggarwala G, Rivera E, Niazi K, Balar N: Comparison of Orbital Atherectomy Plus Balloon Angioplasty vs. Balloon Angioplasty Alone in Patients With Critical Limb Ischemia: Results of the CALCIUM 360 Randomized Pilot Trial. Journal of endovascular therapy: an official journal of the International Society of Endovascular Specialists 2012, 19(4):480-488.

47. Sixt S, Rastan A, Scheinert D, Krankenberg H, Steinkamp H, Schmidt A, Sievert H, Minar E, Bosiers M, Peeters $P$, et al: The 1-year clinical impact of 
rotational aspiration atherectomy of infrainguinal lesions. Angiology 2011, 62(8):645-656.

48. Stoner MC, deFreitas DJ, Phade SV, Parker FM, Bogey WM, Powell S: Midterm results with laser atherectomy in the treatment of infrainguinal occlusive disease. J Vasc Surg 2007, 46(2):289-295.

49. Myers KA, Zeng GH, Ziegenbein RW, Denton MJ, Devine TJ, Matthews PG: Clinical and vascular laboratory determinants for outcome after infrainguinal atherectomy. Cardiovasc Surg 1996, 4(4):449-455.

50. Romano M, Amato B, Markabaoui K, Tamburrini O, Salvatore M: Follow-up of patients with previous vascular interventions: role of multidetector row computed tomographic angiography of the abdominal aorta and lower extremities. The Journal of cardiovascular surgery 2004, 45(1):89-91.

51. Romano M, Mainenti PP, Imbriaco M, Amato B, Markabaoui K, Tamburrini $\mathrm{O}$, Salvatore M: Multidetector row CT angiography of the abdominal aorta and lower extremities in patients with peripheral arterial occlusive disease: diagnostic accuracy and interobserver agreement. European journal of radiology 2004, 50(3):303-308.

52. Taleb M, Burket MW, Cooper CJ: A role for embolic protection in the management of acute limb ischemia. Tech Vasc Interv Radiol 2011, 14(2):75-79.

53. Monaco M, Di Tommaso L, Stassano P, Smimmo R, De Amicis V, Pantaleo A Pinna GB, lannelli G: Impact of blood coagulation and fibrinolytic system changes on early and mid term clinical outcome in patients undergoing stent endografting surgery. Interactive cardiovascular and thoracic surgery 2006, 5(6):724-728.

54. Wholey M: The role of embolic protection in peripheral arterial atherectomy. Tech Vasc Interv Radiol 2011, 14(2):65-74.

55. Suri R, Wholey MH, Postoak D, Hagino RT, Toursarkissian B: Distal embolic protection during femoropopliteal atherectomy. Catheterization and cardiovascular interventions : official journal of the Society for Cardiac Angiography \& Interventions 2006, 67(3):417-422.

56. Shammas NW, Dippel EJ, Coiner D, Shammas GA, Jerin M, Kumar A: Preventing lower extremity distal embolization using embolic filter protection: results of the PROTECT registry. Journal of endovascular therapy : an official journal of the International Society of Endovascular Specialists 2008, 15(3):270-276.

doi:10.1186/1471-2482-12-S1-S13

Cite this article as: Franzone et al.: The role of atherectomy in the treatment of lower extremity peripheral artery disease. BMC Surgery 2012 12(Suppl 1):S13.

\section{Submit your next manuscript to BioMed Central and take full advantage of:}

- Convenient online submission

- Thorough peer review

- No space constraints or color figure charges

- Immediate publication on acceptance

- Inclusion in PubMed, CAS, Scopus and Google Scholar

- Research which is freely available for redistribution 